\title{
LA POLÍTICA PÚBLICA DE ACCESO A LA EDUCACIÓN SUPERIOR PARA LOS ESTRATOS SOCIOECONÓMICOS BAJOS
}

\author{
Marcos Alexander Cárdenas García \\ Universidad Pedagógica Nacional
}

\section{Resumen}

Se presentan los preliminares y una división de capítulos donde se desarrolla el tema. Empieza con las categorías teórico-metodológicas utilizadas para el análisis de las políticas, continúa con una caracterización de la política pública de acceso a la educación superior en Colombia y se enuncian los campos y las condiciones de acceso a la educación superior según el marco normativo.

En este trabajo se propuso examinar la trayectoria de la política pública actual que se ha formulado e implementado respecto al acceso de los estratos socio-económicos bajos a la educación superior.

Palabras clave: acceso, políticas públicas, educación superior, estrato socioeconómico.

El autor: docente de la Maestría en Educación de la Universidad Pedagógica Nacional. Investigador del Grupo de trabajo Politia.

Correo electrónico: macardenasg@hotmail.com

Recibido: 4 de marzo de 2013; evaluado: 21 de junio de 2013; aceptado: 24 de junio de 2013. 


\title{
PUBLIC POLICY REGARDING ACCESS TO HIGHER EDUCATION FOR LOW SOCIOECONOMIC STRATA
}

\author{
Marcos Alexander Cárdenas García \\ Universidad Pedagógica Nacional
}

\begin{abstract}
The preliminary section and a division of chapters where the topic is developed are presented. Then, the theoretical and methodological categories used for the policy analysis are shown and it continues with a characterization of the public policy on access to higher education in Colombia. After, the fields and conditions for such access according to the policy framework are mentioned. In this paper, it was proposed to examine the formulated and implemented current public policy regarding the access to higher education of low socioeconomic strata.
\end{abstract}

Keywords: access, public policies, higher education, socioeconomic strata.

About the author: Professor at the Master of Education of Universidad Pedagógica Nacional. Researcher at "Politia" research group. E-mail: macardenasg@hotmail.com

Received: March 4, 2013; reviewed: June 21, 2013; accepted: June 24, 2013. 


\section{Introducción}

La desigualdad, la falta de oportunidades y la exclusión son características persistentes de las sociedades latinoamericanas en términos de diferencias de ingresos, acceso a servicios, poder e influencia. América Latina es una región con diversidad racial y étnica y los niveles de bienestar no son los mismos entre razas, géneros o grupos étnicos. Como lo indica Ferreira "los indígenas son sistemáticamente más pobres que los no indígenas [...] no existe posibilidad en las mismas condiciones de recibir educación, experiencia laboral o una ocupación". ${ }^{1}$ En ninguno de los países de la región se ha modificado este escenario para una distribución de mejores garantías a los sectores poblacionales o para acercarse más a las distribuciones de ingreso de otras partes del mundo. A pesar de las inmensas transformaciones políticas, sociales y económicas del siglo pasado, estos factores desarrollados históricamente persisten hasta el presente, aunque en formas cambiantes.

Una característica es que "a pesar del incremento en la educación, aún existen fuertes patrones compenetrados de exclusión social y discriminación, que son difíciles de quebrar y que impiden la movilidad hacia niveles superiores". ${ }^{2}$ En Colombia, acceder a la educación superior dejó de ser un factor de desarrollo social y económico, es decir, una garantía para que los más pobres de una sociedad mejoren sus condiciones económicas y sociales.

La pobreza y la desigualdad social y económica se sectorizan geográficamente. Existen evidencias acerca de la dependencia espacial en las medidas de pobreza en Colombia, no solo a escala departamental, sino también municipal. Es cierto que la ubicación geográfica de una población desempeña un papel fundamental en la determinación de las necesidades básicas y de la calidad de vida. Según el Departamento Nacional de Planeación (DNP), en el país existen alrededor de 785 municipios que se encuentran en una situación crítica de pobreza, lo que se traduce en limitadas oportunidades educativas y, por tanto, en una reproducción de sus escasas condiciones sociales y económicas. ${ }^{3}$

Francisco Ferreira, La desigualdad en América Latina ¿Rompiendo con la historia? Serie Desarrollo para todos (Bogotá: Alfaomega colombiana, 2004), 7.

Ferreira, La desigualdad en América Latina, 8.

3 Departamento Nacional de Planeación, Hacia una Colombia equitativa e incluyente. Informe de Colombia objetivos de desarrollo del milenio (Bogotá: DNP, 2005), 83. 
Pocos bachilleres jóvenes o recién egresados logran acceder a la educación superior y una parte apreciable de los que pueden hacerlo tienen la opción de ingresar a programas de baja calidad, elegidos por su facilidad de acceso, sus costos o la posibilidad de llevarlos a cabo en jornadas nocturnas o desescolarizadas. Los sectores más pobres se enfrentan, desde los primeros niveles, a una oferta educativa limitada, sobre todo en las áreas rurales y en las pequeñas poblaciones, lo cual impide que una porción apreciable de población en edad escolar termine, al menos, el ciclo de educación básica.

Por otra parte, la culminación de los estudios secundarios no es garantía para proseguir una educación superior. La baja calidad de la educación secundaria que se imparte en instituciones localizadas en las zonas más pobres de las grandes ciudades y la baja escolaridad en el entorno familiar y social, que conducen, además, a otorgar una débil valoración al trabajo intelectual, excluyen a los estudiantes provenientes de las capas más pobres de las competencias necesarias para ingresar a la educación superior de calidad. Una minoría de personas, muy cualificadas o poderosas, se vuelve competitiva (en el campo laboral, económico, social y político). Esto se ve reflejado en la débil capacidad del Estado para ofrecer bienes públicos clave (en especial la educación), cuyas fallas en la oferta de bienes y servicios públicos casi siempre delimitan el acceso y son excluyentes.

Las políticas que amplían el acceso efectivo a las oportunidades económicas, políticas, de desarrollo humano y social, no solo para la población actual, sino para las generaciones futuras, suelen ser objeto de atención e intervención por parte de los Estados. Tales políticas propenden desde sus enunciados por aumentar el ingreso a educación de alta calidad por mayor participación e influencia en la política y por otros aspectos que demanda una sociedad competitiva como la de hoy. Frente a la educación superior, el Gobierno actual considera crear acciones tendientes a mejorar el acceso de la población más pobre y vulnerable, por medio de la preferencia para este tipo de población, aunque no determina las estrategias; lo justifica porque tiene un impacto en la adquisición, en la economía y en la calidad de vida. La educación se considera, entonces, un instrumento para lograr "la inclusión social". ${ }^{4}$

\section{Justificación}

En Colombia, la pobreza se ha caracterizado por los altos índices de inequidad y se agrega que el conflicto armado convive en las comunidades desde hace ya varias

4 Departamento Nacional de Planeación, Hacia una Colombia equitativa e incluyente, 2005, 83. 
décadas. Es esa pobreza caracterizada por falta de acceso, de un mínimo de recursos, de ser incluidos y de oportunidades la que ha caracterizado la gran mayoría de las estructuras sociales.

De la misma manera, es evidente cómo coexisten el "derecho a la educación" determinado en la Constitución Política y las políticas públicas sobre el terreno, que serían un contraderecho que mantendría socialmente esas situaciones lesivas. Por estas y otras razones, hay condiciones socioeconómicas precarias debidas en gran medida a la misma necesidad "con lo que muchos ya nacen" y a la multiplicidad de planteamientos legislativos y de muchos agentes que cuentan con capacidad de decisión, pero no lo abordan de una manera estructural desde las agendas políticas y las políticas públicas. Las soluciones al problema del acceso han resultado ineficaces por parte de las políticas, ya que es un asunto estructural.

Al observar el contexto, el problema ha existido y sigue vigente, en el sentido de que aún hoy quienes acceden a la educación superior siguen siendo parte de un fragmento de la sociedad privilegiada, en tanto poseen el recurso económico, lograron cumplir con el mérito y tuvieron las suficientes herramientas para continuar y culminar sus estudios. Hasta este momento, como lo afirma Guevara, "se evidencia una estrategia creada que surge para suplir este problema, se configura a partir de la creación de políticas preferenciales de ingreso y exención de matrícula". Muchas veces se presume que con asignar porcentajes de cupos se satisface una demanda y se resuelve un problema social, situación que, de plano, no plantea soluciones, sino que se acentúa aún más la inequidad. Es por eso que el interés por estudiar la política pública de acceso a la educación superior en nuestro país radica en la necesidad de explicar mejor por qué en Colombia es tan precaria la capacidad real que los estratos socioeconómicos bajos tienen para acceder verdaderamente a la educación superior; también surge el interés por determinar bajo qué condiciones se presenta tal situación, tras reconocer que el tema tratado está abordado en agendas de muchos Gobiernos desde tiempos lejanos.

Es indiscutible que, en la actualidad, uno de los temas de discusión y análisis de los investigadores educativos es el que se refiere a la función del Estado en el marco de sus relaciones, no solo con la sociedad, sino con sus agentes, así como a los intereses de ciertos sectores económicos, las instituciones, las agencias, los Gobiernos, sus planes, las políticas y la población objeto de las políticas. Por esto, el análisis de las políticas públicas de acceso a la educación superior aporta a la discusión sobre la efectividad en su implementación y abre un espacio para su comprensión. 
El acceso a la educación superior, como política pública, se aborda desde una revisión de las condiciones y los requisitos de ingreso, de los programas, de los recursos y de los resultados que desea obtener la política, lo que permite una mejor visualización y un entendimiento de las implicaciones, las dificultades o los logros que se tienen al formular este tipo de políticas. Como investigadores, es un deber aportar y explicar los diferentes factores y sus consecuencias y exponer sugerencias que ayuden al mejor entendimiento sobre este tema.

\section{Categorías teórico-metodológicas}

Los estudios sobre políticas públicas permiten un nuevo escenario para interpretar la educación superior y significan un cambio importante que ha reconocido una mejor comprensión de los problemas y tensiones propios de este campo. Quizás el cambio más importante es el que:

[...] dimensiona a la educación como una política pública en relación con los intereses de la sociedad y el espacio público. Desde esta óptica, son agentes de lo educativo y científico el Estado, sus instituciones y agencias, los gobiernos y sus planes y políticas. ${ }^{5}$

Para acercarse al fenómeno de la política de acceso a la educación superior, es necesario partir de los conceptos básicos que conforman el sustento teórico.

\subsection{De la política en general}

La noción de política es muy amplia y los debates que se han generado en torno a su especificidad son múltiples; la discusión ha trasegado por distintos tópicos en los cuales se han visto enfoques de diversas vertientes. Para los propósitos de este trabajo nos remitiremos a una definición que, pese a ser restrictiva en sus alcances, orienta el sentido teórico de este trabajo.

Dada esta aclaración, se podría considerar que la política en general se concibe como "la transacción entre grupos opuestos dentro del consenso y la coerción, entendiendo estos dos conceptos como la confrontación civilizada de grupos sociales", señalado

5 Yves Many y Jean-Claude Thoening, "Marco conceptual, aparición de los problemas públicos y la decisión pública”, en Las políticas públicas (Barcelona: Ariel, 1985), 56. 
por Clausewitz, ${ }^{6}$ cuando mencionaba que es esta "la continuación de la guerra por otros medios". Así, la actividad política busca el aprendizaje de la participación colectiva en proyectos de responsabilidad compartida, la creación de identidades y de oposición social, la movilización en defensa de los propios derechos y la representación de intereses diversos.

\subsection{La política pública}

La política pública y la política en general son similares, aunque no existen plenos consensos que permitan acercarse a sus definiciones. Múltiples autores se han manifestado frente a su definición, en especial después de la Segunda Guerra Mundial. Existen, por lo tanto, enfoques diversos que privilegian perspectivas organizativas, estatales, de movimientos sociales y de las teorías de la comunicación, entre muchos otros.

A partir de lo anterior, se entiende por política pública a "un programa de decisión gubernamental", es decir, "un propósito concreto", "un programa de acción" que busca "la colaboración social, inhibir el conflicto, no siempre con soluciones definitivas, pues la mayoría de las veces sólo pretende lograr un rango de tolerancia". ${ }^{7}$ En este sentido, una de las perspectivas de análisis de la política pública es planteada por Subirats ${ }^{8}$ como el "conjunto de iniciativas, decisiones y acciones del régimen político frente a situaciones socialmente problemáticas que buscan su resolución o su minimización hasta alcanzar un nivel manejable". Según Many y Thoening, ${ }^{9}$ la política pública es "la concreción del Estado en acción, en movimiento, frente a la sociedad y sus problemas, que busca la negociación y el acuerdo en los agentes con poder". Es el conjunto conformado por:

[...] uno o varios objetivos considerados necesarios o deseables, que por medios y acciones sean tratados, por lo menos parcialmente, por una institución u organización gubernamental con la finalidad de orientar el comportamiento de agentes individuales o colectivos para modificar una situación percibida como insatisfactoria o problemática. ${ }^{10}$

Karl von Clausewitz, De la guerra (Barcelona: Idea Universitaria, 1999), 66.

Alejo Vargas, Notas sobre el Estado y las políticas públicas (Bogotá: Almudena editores, 2001), 78.

Joan Subirats, Análisis de políticas públicas y eficiencia de la administración (Buenos Aires: Amorrortu, 1993), 53.

Many y Thoening, "Marco conceptual", 61.

10 Andre Nöel Roth, "Conceptos, teorías y herramientas para el análisis de las políticas públicas", en Políticas públicas: formulación, implementación y evaluación (Bogotá: Aurora, 2002), 31. 
Dentro del marco de las ciencias políticas, el tratamiento de las políticas públicas, exige la comprensión temática desde su aparición y desarrollo. En principio, la expansión de las políticas públicas está asociada en el siglo XX con el crecimiento del tipo de Estado denominado Estado de bienestar, pero en realidad se puede hacer coincidir la aparición de las políticas públicas con el Estado bismarckiano cuando se estudia la posibilidad de extender la actividad del Estado hacia áreas donde su competencia era escasa o nula.

El reconocimiento y auge de las políticas públicas con un determinado tipo de Estado - en nuestro caso, la política de acceso a la educación superior-identificado con la producción de bienes y servicios y con la redistribución de bienes y valores para el consumo, conlleva a que entre la década del treinta y la del sesenta se tratarán de establecer las características del Estado de bienestar en las cuales se manifestó más la intervención directa del Estado, situación que será abordada en el siguiente capítulo.

En la década del noventa, las políticas públicas aparecen altamente condicionadas por las denominadas Reformas de primera y segunda generación. Las primeras estuvieron destinadas a la práctica del ajuste para achicar el déficit fiscal y abrir la economía al circuito internacional. En esta etapa, la reforma trató la apertura de la economía, la desregulación, el ingreso de capitales y las privatizaciones. Según los autores, el punto de partida ha sido denominado Consenso de Washington.

En una segunda etapa, las reformas se basaron en la capacidad de gestión del Estado, su transparencia y la democratización del aparato democrático. Estos cambios introducidos en la transición democrática tampoco llevaron a implementar la gestión gubernamental para la satisfacción de necesidades básicas, con el agravio de la casi imposibilidad de ejercer algún tipo de acción correctiva en los períodos de crisis.

Para el caso de Colombia, revisar el hecho de que los acontecimientos como la expedición de una nueva Constitución y la adquisición progresiva de múltiples compromisos con las bancas multilaterales hicieron que la política pública se transformara y diera un viraje, ya no de una oferta de un bien o servicio por parte del Estado, sino hacia una financiación privada del acceso a la educación superior, lo que confirma un cambio del tipo de Estado en el que se estaban desenvolviendo las políticas. 


\subsubsection{Contenido de la política pública}

Las políticas públicas tienen un contenido que permite presentar su intención en el tiempo. La primera parte de su contenido se denomina "Los ejes del conflicto social", ${ }^{11}$ que llevan a determinar un campo de tematización de los problemas relevantes, con posturas o posiciones de agentes sociales, políticos, económicos, nacionales e internacionales. Esta tiene un orden de temporalidad, por lo que debe analizarse de acuerdo con su momento histórico.

La segunda parte de su contenido se denomina "Programa", donde se exponen los campos de acción de la política pública por parte del Estado o del Gobierno autoritario de turno. Por lo general, se desarrolla mediante planes de acción que contienen unos objetivos, que son los principales reguladores de la conducta que debe seguir la política; unos resultados, definidos como los productos que permiten materializar dichos objetivos y unos impactos, que son los efectos generados en el proceso mismo de definición de los objetivos.

La tercera parte del contenido de las políticas públicas es la de "Objetivos de política", que están determinados a los planes y a la trayectoria de acción de la política pública.

La cuarta parte se define como la "Orientación normativa", que parte desde una lógica jurídica, como normas de tipo sociotécnico, como leyes, decretos, resoluciones y reglas de civilidad que, para el caso de nuestro trabajo, se denominará marco normativo.

El quinto contenido hace referencia a "Los factores de coerción" de la política pública propia de la legitimidad y del monopolio de la fuerza con la que cuenta el Estado.

\subsubsection{El ciclo de la política}

Una herramienta que aparece para el análisis de política pública, apoyados en autores como Many y Thoening ${ }^{12}$ y Roth, ${ }^{13}$ es el momento en el que surge el ciclo de la política, el cual presenta la descripción de cinco distintas fases del proceso evolutivo de una política pública.

Oscar Oszlak, Estado y sociedad: las nuevas reglas de juego (Buenos Aires: Oficina de publicaciones del CBC, 1997), 41.

12 Many y Thoening, "Marco conceptual", 93.

13 Roth, "Conceptos, teorías y herramientas para el análisis de las políticas públicas", 31. 
La primera fase se denomina "Identificación de un problema", ${ }^{14}$ que es cuando se aprecian los acontecimientos por parte de los agentes involucrados y se define un problema socialmente relevante, se describe su naturaleza, sus causas, se hace referencia a la duración y su dinámica y se movilizan los afectados, quienes a su vez plantean unas consecuencias del problema, con la finalidad de su institucionalización por medio de su incorporación en una agenda pública.

La segunda fase se denomina "Formulación de soluciones o acciones", ${ }^{15}$ en que se elaboran las respuestas y un estudio de soluciones por parte de la autoridad pública. Existen varios modelos de inscripción del problema ante la autoridad. ${ }^{16}$ El primero hace referencia a la movilización de ciertos agentes en pro de una causa o de varios intentos para movilizar a otros ciudadanos. El segundo modelo es la oferta política; con el fin de ganar adeptos, el gobernante o la autoridad pública ofrece ciertas soluciones a algunos problemas relevantes del momento. El tercer modelo tiene que ver con la mediatización; en él, los medios de comunicación hacen una fuerte presión para que las autoridades asuman el problema. El cuarto modelo es la anticipación, en el que la Administración pública se adelanta al problema y decide actuar antes de que existan las movilizaciones; por último, está el modelo de la acción corporativista silenciosa, en la cual se inscribe el problema por medio de ciertos grupos organizados privilegiados y con alta influencia sobre la agenda pública.

En la tercera fase se enfrenta la "toma de decisión"17 por parte de la autoridad pública, cuando se hace necesaria la creación de una coalición para alcanzar consensos, basados en una legitimación de la política elegida, es decir, una política efectiva frente al problema o que las decisiones dentro del conjunto de las posibles opciones sean las más viables política, social y económicamente.

La cuarta fase se llama "Implementación". ${ }^{18}$ Es la fase más importante de todas, debido a que es la ejecución de la política sobre el terreno; es donde hay un marco normativo, se movilizan medios y recursos por parte de la autoridad pública, existen objetivos, cronogramas y programas, interfieren otros agentes no estatales durante la gestión y la administración de la política, cuyo principal resultado es una producción de efectos sobre el terreno donde esta se aplica. Los enfoques de

\footnotetext{
Roth, "Conceptos, teorías y herramientas para el análisis de las políticas públicas", 41.

Roth, "Conceptos, teorías y herramientas para el análisis de las políticas públicas", 43.

Many y Thoening, "Marco conceptual", 67.

Many y Thoening, "Marco conceptual", 68

Many y Thoening, "Marco conceptual", 69
} 
implementación constituyen el lazo entre el proceso de decisión de una política y sus procesos de ejecución. Existen cuatro categorías que van en función de la concepción utilizada para su realización práctica.

El primer enfoque, que hace referencia autores como Many, ${ }^{19}$ se denomina top-down o del centro hacia la periferia, basado en el trabajo administrativo convencional que se desarrolla de arriba (top) hacia abajo (down). Cuenta con supremacía jerárquica de la autoridad, con una distinción entre el universo político y el mundo administrativo y con un principio de búsqueda de la eficiencia; su principal obstáculo es un único direccionamiento de órdenes por parte de la Administración, lo que descarta la participación y el diálogo de otros actores involucrados dentro de la implementación de la política.

El segundo enfoque se denomina bottom up ${ }^{20}$ en dirección contraria al anterior. En este caso, se trata de partir de los comportamientos concretos en donde existe el problema, para construir la política pública poco a poco, con reglas, procedimientos y estructuras organizativas por medio de un proceso ascendente o por retrocesos y de superación de errores, en vez de descendente.

El enfoque del buen gobierno o governance ${ }^{21}$ se centra más en la renovación del proceso de implementación que en los resultados; parte del supuesto de que "todo Gobierno" y "todo mercado" han fracasado y trata de crear escenarios, estrategias y mecanismos de participación o de inclusión de organizaciones no estatales para aumentar las posibilidad de éxito de la gestión. Reconoce una interdependencia de los sectores público y privado y voluntario $(\mathrm{ONG})$ por medio de un margen de gobernabilidad política por parte de las autoridades públicas.

El enfoque de gestión pública ${ }^{22}$ se caracteriza por tener aspectos del contenido material de la política (objetivos y diseño) y del contexto y de los recursos disponibles para su implementación. Este modelo presenta cinco condiciones bajo las cuales una decisión política puede llegar a tener éxito en su implementación.

La primera hace referencia a que el programa debe estar fundamentado en una teoría sólida relacionada con el cambio de comportamiento del público necesario para la

\footnotetext{
Many y Thoening, "Marco conceptual", 16.

Many y Thoening, "Marco conceptual", 18.

Many y Thoening, "Marco conceptual", 19.

Many y Thoening, "Marco conceptual", 19.
} 
realización de los objetivos. La segunda tiene que ver con la ley o la decisión política, debe contener directrices de actuación precisas y estructurar el proceso de implementación, de manera que maximice la probabilidad de que los destinatarios se comporten según lo previsto. Tercera, los dirigentes de los entes responsables deben disponer de capacidad política y de gestiones importantes y tener un compromiso con los objetivos de la misma. Cuarta, el programa debe disponer de apoyos activos durante todo el proceso de implementación por parte de grupos organizados de electores y por algunos legisladores; los tribunales deben estar a favor o mantenerse en una postura neutral. Quinta, los objetivos legales de la política no deben debilitarse con la aparición de otras políticas que entren en conflicto o que atenten con debilitarla o por cambios socioeconómicos que debiliten los fundamentos técnicos de la teoría o el apoyo político de quienes la respaldan.

En el enfoque contingente ${ }^{23}$ se hace necesario considerar los procesos de implementación como procesos eventuales, es decir, difícilmente previsibles; con ello el interés se centra en las condiciones de efectividad de las políticas públicas. Los instrumentos para implementar las políticas públicas deben ser coordinados, deben expedirse nuevas reglamentaciones, como sanciones o permisos que le den viabilidad a la implementación, se deben tener transferencias financieras suficientes, una prestación efectiva de los bienes y servicios por parte de los particulares, una reglamentación clara de procedimientos y una persuasión derivada en campañas informativas.

En Colombia, las políticas públicas no han existido siempre: aparecen en condiciones específicas, como una mirada crítica a los diferentes programas que ha venido implementando el Estado. Quizá con los planes de desarrollo económico y social en nuestro país, formulados desde 1970, se hizo más notable el papel del sector social y con este el de la educación. Antes de 1970, Colombia y la mayoría de los países de América Latina siguieron las orientaciones de la Conferencia Económica para América Latina (Cepal).

Las políticas públicas en Colombia se han apreciado como decisiones y orientaciones que han emanado de manera discrecional —y algunas veces arbitraria— de los gobernantes del país en diferentes períodos (top-down); la política pública actual de acceso a la educación de los estratos socioeconómicos bajos puede ubicarse dentro de esta vertiente. Otros enfoques las han visto como el resultado de procesos en

23 Many y Thoening, "Marco conceptual", 20. 
los que intervienen diferentes actores en un marco institucional dado. No es fácil determinar desde cuándo existen políticas públicas en Colombia y menos aún el surgimiento de políticas públicas de acceso para la educación superior, como lo analizaremos en el siguiente capítulo.

\subsection{La inclusión, la integración y la equidad}

La investigación planteó el concepto de acceso como punto de partida, pero surgía la duda de si este hacía referencia al momento en el que se "accede", en este caso a una oferta de un bien o un servicio público, pero a su vez un servicio regulado por el Estado y por todas las lógicas del mercado globalizado. Esto no solo al momento de ese "acceder a" sino de toda una transformación, de un pensamiento y obrar, de una manera mucho más compleja de concebir a la educación. Por eso, el concepto de inclusión se aborda debido a su presencia en discursos y políticas que han aportado sus apreciaciones al respecto.

Autoras como Rodríguez de Salazar consideran que

[...] la educación inclusiva implica que todos los niños y niñas de una determinada comunidad, puedan aprender juntos, independientemente de sus condiciones personales, sociales o culturales; comprende también a aquellos que presentan una discapacidad. Se trata de un modelo de escuela en la que no existen requisitos de entrada ni mecanismos de selección o discriminación de ningún tipo [...] supone educar en el respeto a las peculiaridades de cada estudiante y en el convencimiento de que las diferencias son el resultado de un complejo conjunto de factores tanto individuales como socioculturales, que interactúan. ${ }^{24}$

La "inclusión" no es una modificación o ajuste de una serie de elementos presentes en un proceso educativo (objetivos, materiales, actividades, etc.), sino que "supone un cambio profundo de la estructura, funcionamiento y modelo pedagógico, con la finalidad de dar respuesta a todos y cada uno de los estudiantes, incluidos aquellos que presentan una discapacidad, pero no solamente a ellos". 25

24 Nahir Rodríguez de Salazar, "Proyecto Manos y pensamiento-Red de Instituciones Formadora de Formadores" en Manos y pensamiento: inclusión de estudiantes sordos a la vida universitaria, comp. Claudia Rozo (Bogotá: Kimpres Ltda., 2009), 74.

25 Diana Peláez, Johana Pinzón y Claudia Marcela Toscano, "Permanecer en el contexto universitario de la Universidad Pedagógica Nacional: Una propuesta para la permanencia de los estudiantes en situación de discapacidad" (Tesis de pregrado, Universidad Pedagógica Nacional, 2009), 12. 
Otras posturas que nos orientan para una definición de "inclusión" la concibe "[...] como un conjunto de procesos orientados a eliminar o minimizar las barreras que limitan el aprendizaje y la participación de todo el alumnado". Son las barreras las que "se pueden encontrar en todos los elementos y estructuras del sistema: dentro de las escuelas, en la comunidad, y en las políticas locales y nacionales". ${ }^{26}$

Para otros autores como Pérez Morgan, la inclusión es un concepto basado en "el trabajo conjunto en América por el Instituto Interamericano del Niño (UN) y la Confederación Interamericana de Asociación de Padres y Personas Discapacitadas y organizaciones gubernamentales y profesionales" que acordaron la siguiente definición:

[...] cuando políticas, programas, servicios sociales y comunidad se organizan, planifican, operacionalizan o se adaptan para garantizar la no-exclusión y la aceptación de diferencias, junto al desarrollo pleno, libre e independiente, en un contexto de reconocimiento sobre la importancia de facilitar acceso igualitario a la solución de necesidades en la propia comunidad, en alternativas lo menos segregadas posible que garanticen la Inclusión de la niñez y de jóvenes con discapacidad y con diferencias culturales entre otras. ${ }^{27}$

La inclusión supone eliminar una cultura que discrimina y excluye por acción u omisión. De modo paralelo, implica aceptar el derecho que tiene cada uno de ser diferente. No hay ninguna razón inherente a la persona con discapacidad, con limitados recursos económicos o por su raza u origen por la cual la persona deba quedar fuera del sistema educativo, del trabajo, de las relaciones y redes sociales o del ejercicio de sus derechos ciudadanos en general. La no-inclusión supone una estigmatización o limitación impuesta por otros.

Según la Organización Mundial de Personas con Discapacidad, 28 "inclusión" significa:

[...] ser apreciado y respetado en el marco de la vida social, económica, política y cultural de su propia comunidad; ser apreciado por sus habilidades y talentos; tener las mismas oportunidades y ánimo para crecer y llegar a ser la persona que uno quiere llegar a ser; y, creando relaciones de confianza y

26 Viviana Cantor y Carolina Gómez, "Hacia una cultura inclusiva" (Tesis de pregrado, Universidad Pedagógica Nacional, 2009), 26.

27 Blanca Pérez Morgan, La inclusión de la niñez con discapacidad (Montevideo: Proder, 2002), 17.

28 Organización Mundial de Personas con Discapacidad, "Plan estratégico 2002-2006. Trabajando juntos para forjar nuestro futuro", http://latinamerica.dpi.org/3PLANESTRATEGICOOMPD_000.doc (acceso mayo 13, 2010), 17. 
amistades, desarrollar lo mejor que exista en cada uno y crear el tipo de vida que uno aprecia.

No es fácil describir la definición que aporta la legislación colombiana respecto al concepto de inclusión. La que aporta el Ministerio de Educación Nacional:

[... el el término inclusión se resalta como una actitud que engloba el escuchar, dialogar, participar, cooperar, preguntar, confiar, aceptar y acoger las necesidades de la diversidad. Concretamente tiene que ver con las personas, en este caso, las personas con discapacidad, pero se refiere a las personas en toda su diversidad. El incluir implica el dejar participar y decidir a otros que no han sido tomados en cuenta. Una educación incluyente ve a todos los estudiantes como capaces de aprender y anima y honra todos los tipos de diversidad, incrementando la posibilidad de una igualdad de oportunidades y con ello, la mejora de la calidad educativa. Una educación incluyente descansa en una actitud y en un sistema de valores y creencias. La educación inclusiva se centra pues en cómo apoyar las cualidades y detectar las necesidades de cada uno y de todos los estudiantes en la comunidad educativa, para que se sientan bienvenidos y seguros y alcancen el éxito. ${ }^{29}$

La "inclusión" en las Instituciones de Educación Superior (IES) tendría que analizarse desde varios aspectos:

[...] cambios en el manejo de la vida personal, en el método de estudio, en las formas de convivencia, adaptación muchas veces a la ciudad, a los requerimientos económicos, etc. Todas estas circunstancias podrían redundar en la aparición, por ejemplo, de cuadros de depresión, problemas de autoestima, el no reconocimiento de las capacidades, baja motivación o vinculación a grupos de dudosa reputación donde logran finalmente el reconocimiento. ${ }^{30}$

Otro concepto que aparece en la discusión y en múltiples discursos y políticas es el de "integración", ya que según los referentes teóricos, está inmerso en el de inclusión. Debido a las dificultades en el uso y las actitudes frente a la integración, existe una tendencia a cambiarlo por el concepto de inclusión, que es más amplio.

\footnotetext{
Ministerio de Educación Nacional, Lineamientos de politica para la atención educativa a poblaciones vulnerables (Bogotá: Autor, 2005), 2.

30 Martha Lilia Mayorga, ¿Una inclusión excluyente? Una mirada a los requerimientos de un programa de inclusión en IES (Bogotá: Ministerio de Educación Nacional, 2008), 56.
} 
Para ampliar el panorama y destacar la importancia de estos dos elementos para esta investigación y de sus diferentes definiciones es importante abordarlo. Los vocablos integración e inclusión, aunque tengan significados semejantes, se emplean para expresar situaciones de inserción diferentes y se fundamentan en posicionamientos teórico-metodológicos divergentes. El vocablo integración se refiere de manera más específica a la inserción escolar de alumnos con deficiencia en las escuelas comunes, mas su empleo alude a la designación de alumnos agrupados en escuelas especiales para personas con deficiencia, incluso, en clases especiales, grupos de recreo y residencias para deficientes; en la integración escolar, el alumno tiene acceso a las escuelas por medio de un abanico de posibilidades educacionales, que va desde la inserción en las salas de clase de enseñanza regular hasta la enseñanza en escuelas especiales. ${ }^{31}$

La autora María Egler hace referencia a que la inclusión:

[...] cuestiona no sólo las políticas y la organización de la educación especial y regular, sino también el propio concepto de integración; es incompatible con la integración, pues prevé la inserción escolar en forma radical, completa y sistemática. Todos los alumnos, sin excepciones, deben frecuentar las aulas de enseñanza regular. ${ }^{32}$

El objetivo de la integración es incorporar a un alumno o un grupo de alumnos que ya fue excluido, mientras el de la inclusión es no dejar a nadie por fuera de la enseñanza regular, desde el inicio de la vida escolar. Las escuelas inclusivas proponen un modo de organización del sistema educacional que considera las necesidades de todos los alumnos y estructure en función de esas necesidades. ${ }^{33}$

Para autores como Valladares, la integración es:

[...] el proceso que posibilita a la persona desarrollar su vida escolar en establecimientos regulares de enseñanza, atendiendo y valorando sus capacidades cognitivas, afectivas y sociales [...]. Esto puede ser real con las condiciones y

\footnotetext{
María T. Egler, "El derecho a la diferencia en la igualdad de los derechos" en Manos y pensamiento: inclusión de estudiantes sordos a la vida universitaria, comp. Claudia Rozo (Bogotá: Kimpres Ltda., 2009), 39.

32 Egler, "El derecho a la diferencia en la igualdad de los derechos", 38.

33 Egler, "El derecho a la diferencia en la igualdad de los derechos", 38.
} 
medios adecuados, para participar del conjunto de actividades educativas en un medio de relación con pares. ${ }^{34}$

En definitiva, va más allá de mantener al estudiante en forma presencial o física en los salones, exige la posibilidad de acceder a todas las oportunidades de interacción social y académicas que el medio educativo le brinde y destaca las potencialidades que deben ser estimuladas de manera permanente. Valladares complementa con el término de integración social:

[Es el] proceso que vive toda persona al desempeñar roles y funciones que se esperan de ella en los distintos sectores en que está organizada una sociedad: familia, trabajo, educación, vivienda, salud y otros. Las posibilidades de esta integración están determinadas por la capacidad y el deseo del individuo de ejercer tales roles, su correspondencia con las necesidades y expectativas sociales y las oportunidades o barreras que le ofrezca el medio. ${ }^{35}$

La equidad también se presenta como concepto reiterativo dentro de los diferentes discursos. Gómez afirma que:

[...] el tema está abandonado hasta el año 2000 y que ahora ya hace parte de las prioridades en los planes políticos, de los proyectos de ley, de las protestas de estudiantes, de investigaciones del sector público y privado en toda América Latina. ${ }^{36}$

Quizá la tendencia regional consiste en que la equidad quedó instalada en la agenda política de los países como resultado de las políticas y el modelo estatal anterior de bienestar; eso forma parte de la discusión sobre el papel del Estado y el modelo de desarrollo de las políticas públicas en América Latina.

Existen experiencias de investigación sobre el tema en Chile. Según Canales:

En el ámbito de la educación escolar, la equidad ha sido entendida tradicionalmente como un mínimo que debe garantizarse a toda la población (la misma concepción existe en Colombia) [...] sin embargo, no ha ocurrido lo mismo

\footnotetext{
María Angélica Valladares, Texto de apoyo para un proceso de integración educativa (Santiago: Fonadis, 2001), 71. Valladares, Texto de apoyo, 77.

36 Víctor Manuel Gómez, "La política de equidad social y la transformación de la educación superior" (Ponencia presentada al Coloquio Universidad, Estado, sociedad, Bogotá, 7-8 noviembre, 1996), 16.
} 
con la educación superior. Este nivel se ha entendido como un nivel avanzado al que tienen acceso sólo quienes poseen los méritos académicos suficientes. ${ }^{37}$

¿Qué significa "suficientes"? Aquellos que están más dotados social y culturalmente y los que no lo están, ¿nunca podrán acceder porque no tienen los méritos? Aquellos que han tenido una educación continua y de calidad obtendrán los resultados esperados, pero los que tienen una educación insuficiente, de menor competitividad, ¿no tienen derecho a la educación superior?

Existe una reflexión de Fuentes acerca del mérito y es que antes que el mérito, existen los derechos de todos los hombres, sean o no los mejores. ${ }^{38}$ Canales se refiere al problema del acceso de jóvenes indígenas a la Universidad Nacional: "Aquí los derechos se volvieron oportunidades". ${ }^{39}$

Existe una exclusión educativa en el mundo frente a la educación de América Latina y, si no fuera suficiente, entre los mismos colombianos hemos generado otra: la del acceso al ámbito público y al privado. Y a la vez existe otra entre lo rural y lo urbano, entre indígenas, negros y blancos, pobres y ricos con educación. El problema de la exclusión, falta de oportunidades y equidad sigue vigente y requiere políticas públicas y acciones de Estado urgentes, para lo cual se necesita voluntades políticas que repartan las oportunidades de otra manera.

Somos diferentes como seres humanos, tenemos perspectivas diversas, aprendemos en formas distintas y buscamos fines que no siempre son los mismos. No obstante, en cuanto a los beneficios para las sociedades, somos radicalmente iguales, tenemos derechos como: la vida, la educación, la salud, el trabajo, la dignidad etc., lo cual hace parte de la constitución política del Estado Colombiano. ${ }^{40}$

Es una gran disyuntiva: isomos radicalmente diferentes o somos iguales y queremos ese tratamiento? Como no se desean discusiones, analizaremos por qué el concepto de "equidad" es importante dentro de los debates actuales sobre el acceso a la educación universitaria estatal.

37 Andrea Canales, "Expansión de la educación superior en Chile", http://www.revistahumanum.org/revista/ expansion-de-la-educacion-superior-en-chile-hacia-un-nuevo-enfoque-sobre-la-equidad-y-calidad-delsistema/ (acceso junio 18, 2010), 31.

38 Carlos Fuentes, El sarko y sego: fundamentales y diferencias (Bogotá: Ariel, 2007), 41.

39 Canales, "Expansión de la educación superior en Chile", 24.

40 Vargas, Notas sobre el Estado y las politicas públicas, 59. 
La equidad se compara con justicia en muchos espacios de discusión. Según Terricabras:

A veces se han equiparado las nociones de "igualdad humana" y de "justicia" especialmente con "justicia social". Esta es frecuente cuando se habla de justicia distributiva (o redistributiva) o cuando la distribución o la redistribución afecta bienes materiales. Según ello, lo justo es la distribución igual, independientemente del aumento o disminución de beneficios que puedan darse de ella. ${ }^{41}$

Difícil situación en un sistema económico como el colombiano, de corte económico neoliberal: "La igualdad es un concepto poco grato para el neoliberalismo: todos somos desiguales y eso es precisamente lo que mueve el mercado [...] la posibilidad que cada individuo" aproveche sus "diferencias naturales" y "los beneficios recibidos". ${ }^{42}$ De lo que se trata en justicia es de "promover la equidad, es decir, promover las diferencias productivas entre los individuos para que puedan competir, ser útiles social y económicamente. Equidad e igualdad se oponen pues esta última, según los neoliberales, pretende homogenizar de forma artificial a los individuos. Si se respetan las desigualdades y hubiera un ente igualador se perdería el interés de competir". ${ }^{43}$

En la sociedad actual colombiana, la situación de desigualdad es evidente. El acceso a la educación, en especial a la universitaria, depende del ingreso mensual de una persona o de su grupo familiar, de las condiciones previas de formación y de las pruebas de Estado, en suma, de las condiciones materiales que posibilitan el acceso a un tipo de educación y, con ello, a una capacidad económica determinada.

En una organización de Estado neoliberal las diferencias son evidentes: van desde el lugar en donde se vive, el consumo de bienes y servicios, la salud y hasta el derecho a la educación. En el caso de la educación superior colombiana, no existe un ente regulador de la distribución de oportunidades frente al acceso; tal vez por eso en la competencia entre ricos y pobres, cuanto más y menos favorecidos, más dotados o menos dotados siempre va a existir un desbalance.

Hasta este momento se resalta que una estrategia creada que surge para suplir este problema se configura a partir de la creación de políticas preferenciales de ingreso

\footnotetext{
Josep María Terricabras, "Equidad", en Diccionario de Filosofía (Buenos Aires: Ariel, 2007), 34.

Miñana y Rodríguez, "La educación en el contexto neoliberal", 6.

Miñana y Rodríguez, "La educación en el contexto neoliberal", 6.
} 
y exención de matrícula; como lo menciona Guevara, "presumen que asignar porcentajes de cupos supone que ese solo hecho satisface una demanda y resuelve un problema social" ${ }^{44}$ Mayorga ${ }^{45}$ menciona cómo la inclusión requiere de la transformación de las instituciones educativas para que puedan dar una respuesta pertinente, de calidad y con equidad a las diferencias de las personas y grupos. Por ser escaso el recurso de la educación superior, tiende a ser un factor de mayor discriminación en nuestra sociedad para los grupos de menores recursos económicos y condiciones de movilidad para el acceso a las entidades públicas y privadas.

Para estos grupos llamados "vulnerables" 46 la educación superior se ha convertido en el único incentivo para mantenerse en la educación media y en la única posibilidad de mejorar las condiciones de vida y de escapar de la presión que los grupos armados al margen de la ley ejercen para reclutar jóvenes de estos estratos económicos y de esas regiones apartadas. ${ }^{47}$ La política actual propende por una inclusión desde su formulación, pero la realidad no permite establecer esa verdadera relación entre inclusión, equidad y, por supuesto, acceso a la educación superior, ya que el abordaje del total de la población que debe y puede estar educándose es muy débil si solo tenemos en cuenta el cubrimiento que se hace por parte de la política a una población objeto. Para eso, el instrumento que ha utilizado el Estado colombiano para ubicar y seleccionar a los posibles beneficiarios es el estrato social, con herramientas como la focalización y el gasto público para su implementación.

\subsection{La población de estratos bajos, la focalización y el gasto público}

Desde el final de la Segunda Guerra Mundial y hasta el inicio de la década del setenta, nuestra cultura sobre la pobreza estuvo muy asociada con subdesarrollo y bajos ingresos, en tanto esa era la visión de organismos como el Banco Mundial, cuya política y sus programas de reducción de la pobreza en los países del tercer mundo estaban enraizadas en las ideas de desarrollo como crecimiento económico y aumento de los ingresos. Paralelo a ese esquema de pensamiento, se desarrollaron

44 René Guevara, "Minorías y universidad estatal en Colombia: aproximaciones a un estudio de políticas públicas universitarias" (Ponencia presentada en Coloquio internacional Análisis y evaluación de políticas públicas en Colombia: experiencia, teorías y métodos en debate. Bogotá, 4 de noviembre, 2007), 72.

45 Mayorga, ¿Una inclusión excluyente?, 32.

46 Recordemos que el Ministerio de Educación Nacional define como población vulnerable a "un grupo de personas que se encuentran en estado de desprotección o incapacidad frente a una amenaza a su condición psicológica, física y mental, entre otras. En el ámbito educativo este término hace referencia al grupo poblacional excluido tradicionalmente del sistema educativo por sus particularidades o por razones socioeconómicas". Ministerio de Educación Nacional, Lineamientos de política para la atención, 62.

47 Mayorga, ¿Una inclusión excluyente?, 35. 
políticas y programas de inversión en formación de capital, ayudas para el desarrollo (construcción de infraestructura física y social, como hospitales y universidades) y asistencia pública. ${ }^{48}$

Treinta años después, la pobreza continúa siendo vinculada con las ideas de subdesarrollo y bajos ingresos y su reducción se sigue pretendiendo mediante el crecimiento económico. Sin embargo, ha habido cambios no solo en el pensamiento dominante sobre las nociones de pobreza, salud y desarrollo y sobre los enfoques y métodos de su estudio, medición e intervención, sino también en las versiones alternativas que explican el subdesarrollo y la pobreza en los enfoques y procedimientos que estas proponen para su superación.

A partir de mediados de la década del setenta, si bien la pobreza seguía identificándose con subdesarrollo y su superación con crecimiento económico; sin embargo, se concebía que:

[... el el logro del crecimiento económico y la consecuente reducción de la pobreza pasaba por poner en práctica una concepción de desarrollo que ahora hacía funcional del crecimiento económico y la inversión en recurso humano antes que en formación de capital. Para desarrollar el recurso humano era imperativo satisfacer necesidades básicas de alimento, vivienda, vestido, agua potable, saneamiento, transporte público, salud y educación. ${ }^{49}$

Para el efecto, se diseñaron políticas de desarrollo rural e infraestructura urbana y de provisión de servicios básicos como salud y educación. Los instrumentos de intervención usados fueron programas de desarrollo rural integrado, ayudas y préstamos basados en proyectos específicos.

[El discurso dominante] logró articular discursos alternativos que sostenían que la satisfacción de las necesidades básicas no podría darse sin enfoques participativos que permitieran una mejor identificación y solución de las mismas con la participación de los pobres. En esta concepción de desarrollo

\footnotetext{
Luis Ignacio Román, Pobreza, desigualdad de oportunidades y políticas públicas en México (México: Fundación Konrad Adenauer, 2001), 24.

49 Román, Pobreza, desigualdad de oportunidades y politicas públicas en México, 20.
} 
se buscó una mejor interacción entre lo económico y lo social, y en ello el Estado debería jugar un importante papel interventor. ${ }^{50}$

De acuerdo con Brock, Cornwall y Gaventa, ${ }^{51}$ en la década del ochenta inició el discurso neoliberal de Gobierno, orientado a solucionar la crisis económica de la época mediante la puesta en práctica de programas de ajuste estructural, reducción del gasto fiscal y disminución del impacto de estos en la pobreza por medio de los llamados fondos sociales.

Este discurso retomó la idea de crecimiento económico como expresión de desarrollo, pero ahora retiraba el Estado de la economía y abría las puertas a las fuerzas del mercado. Los Gobiernos perdieron autonomía para desarrollar sus agendas y programas de política económica y social y cayeron bajo el condicionamiento de las políticas establecidas por los prestamistas internacionales. Los pobres fueron ahora considerados agentes económicos racionales "cuyo comportamiento debería garantizarles aprovechar las oportunidades del mercado y de la prosperidad económica venidera". ${ }^{2}$

La conclusión de la teoría de la justicia de Rawls, es que "se debe dar tratamiento preferente a los más débiles, en este sentido, un objetivo primordial en la política social es reducir la pobreza". ${ }^{53}$ Según Van de Walle, "la eficiencia de la política es entonces función de la forma en que se defina y mida la pobreza, de un lado, y de otro de qué tan explícito es el objetivo de política". ${ }^{44}$ En la sección anterior hemos enunciado los criterios adoptados por la estratificación socioeconómica para evaluar capacidad de pago o de endeudamiento, que en nuestro caso equiparamos a pobreza. Esto significa que la estratificación ha sido diseñada para focalizar la población con baja capacidad de pago o población pobre. Por focalización —que es un instrumento y no un objetivo de política por sí mismo- entendemos un "intento deliberado por dirigir los beneficios del gasto público a los pobres a través de medios que buscan seleccionarlos como sus beneficiarios directos", ${ }^{55}$ aunque

50 Karen Brock, Andrea Corwall y John Gaventa, Power, Knowledge and Political Spaces in the Framing of Poverty Policy (Brighton: Institute Of Development Studies, 2001), 61.

51 Brock, Cornwall y Gaventa, Power, Knowledge and Political Spaces, 22.

52 Román, Pobreza, desigualdad de oportunidades y politicas públicas en México, 71.

53 Lucía Mina Rosero, "Estratificación socioeconómica como instrumento de focalización", Economía y desarrollo, 3, núm. 1 (2004): 2.

54 Jurgen Van de Walle, "Incidence and Targeting: An Overview of Implications for Research and policy" en Public Spending and the poor. Theory and Evidence (Baltimore: Banco Mundial, John Hopkins University Press, 1995), 605.

55 Van de Walle, "Incidence and Targeting", 605 
en algunos contextos, la focalización es vista en contraposición a las políticas que son aplicadas a toda la población.

Según Rosero, "la focalización puede hacerse llevando a los individuos interesados a auto-focalizarse" ${ }^{56}$ como ocurre al implementar programas de alimentación en comedores públicos, empleo con muy bajas remuneraciones o al aplicar indicadores predeterminados por los técnicos, mediante los cuales se identifica la población objetivo. Ambos métodos han sido implementados en el país y, en el último caso, se han adoptado indicadores como el Sisbén, utilizado, entre otros propósitos, para asignar subsidios en el sector de la salud o educación; también se utilizan el Índice de Necesidades Básicas Insatisfechas (NBI), con el que se han distribuido los ingresos del Estado entre los diferentes departamentos, el Índice de Condiciones de Vida (ICV), en algunos casos y el criterio de estratificación socioeconómica, que es el que nos ocupa.

Frente a la educación superior, el Gobierno actual considera crear acciones "tendientes a mejorar el acceso de la población más pobre y vulnerable" como este la define, por medio de "la preferencia para este tipo de población", aunque no determina las estrategias; lo justifica por tener "un impacto en la adquisición, en la economía, en la calidad de vida". La educación, según el Gobierno actual, "se considera entonces un instrumento para lograr la inclusión social". ${ }^{57}$

Una de las tareas centrales que desarrolló el Gobierno, una vez fijado el sentido de la política y la normatividad acerca de "la focalización del gasto social", fue la de diseñar la herramienta que garantice "la identificación de los más pobres entre los pobres para la entrega de subsidios para programas sociales". Esta tarea fue encomendada a la Misión Social del Departamento Nacional de Planeación, que diseñó y adoptó el Sisbén (Sistema Integrado de Selección de Beneficiarios) $)^{58}$ mediante Resolución 65 de marzo 25 de 1994 del Conpes Social. ${ }^{59}$ En desarrollo de tal mandato, a partir de enero de 1995 se adoptó la ficha actual del Sisbén para la identificación de hogares y personas pobres. Este instrumento fue recomendado por el Consejo Nacional de Seguridad Social en Salud para la selección de beneficiarios del aseguramiento en el régimen subsidiado de Seguridad Social en Salud por Acuerdo del 23 de diciembre

Rosero, "Estratificación socioeconómica como instrumento de focalización", 29.

57 Ministerio de Educación Nacional, Lineamientos de política para la atención, 18.

58 Departamento Nacional de Planeación, Consejo Nacional de Política Económica y Social, Focalización del Gasto Social en las Entidades Territoriales, Conpes Social 022 (Bogotá: DNP, 1995), 11.

59 Departamento Nacional de Planeación, Consejo Nacional de Política Económica y Social, Focalización del Gasto Social, Conpes Social 040 (Bogotá: DNP, 1997), 11. 
de $1995 .{ }^{60}$ El Sisbén forma parte de un conjunto de herramientas gerenciales diseñadas por expertos que trabajan con el Banco Mundial y puestas al servicio de los gerentes y tomadores de decisiones políticas para "entregar servicios sociales subsidiados y focalizados en los más pobres" ${ }^{61}$ Tradicionalmente, el Banco Mundial ha privilegiado la entrega de subsidios focalizados en vez de subsidios universales y ha promovido su uso por parte de Gobiernos.

Dentro del plan sectorial "La revolución educativa 2002-2006", que se refiere a los lineamientos de la política para la atención educativa de poblaciones vulnerables, se propusieron procesos y acciones de los cuales los beneficiarios directos son los colombianos que forman parte de lo que la Ley General de Educación identificó como las poblaciones vulnerables, o sea, "personas que, por su naturaleza y determinadas circunstancias, se encuentran en mayor medida expuestos a la exclusión, la pobreza y los efectos de la inequidad y la violencia de todo orden". ${ }^{62}$

\subsection{La estratificación socioeconómica}

La estratificación socioeconómica ha sido un instrumento utilizado por el Estado colombiano para la consideración de potenciales beneficiarios de la política de acceso a la educación superior, establecido como parámetro para clasificar la población en "distintos grupos de personas que podrían tener características sociales y económicas similares" ${ }^{63}$ Por ejemplo, es utilizado para definir tarifas diferenciales de los servicios públicos, asignar subsidios, focalizar programas sociales y determinar las tarifas del impuesto predial unificado de las viviendas. ${ }^{64}$

La estratificación socioeconómica la basa el Estado, en la calidad de las viviendas como una aproximación a la calidad de vida de las personas que las habitan. ${ }^{65}$ Por eso, investiga las características físicas de las viviendas mediante un censo de manzanas, cuadras o viviendas individuales y conforma los estratos mediante la aplicación de un método estadístico. Las variables que se investigan sobre las

60 Departamento Nacional de Planeación, Consejo Nacional de Política Económica y Social, Focalización del Gasto Social, 1997, 11.

61 Rosero, "Estratificación socioeconómica como instrumento de focalización", 56.

62 Ministerio de Educación Nacional, La revolución educativa (Bogotá: Autor, 2002), 84

63 Departamento Nacional de Planeación, Consejo Nacional de Política Económica y Social, Reforma del Sistema de Focalización Individual del Gasto Social, Conpes Social 055 (Bogotá: DNP, 2001), 62.

64 Departamento Nacional de Planeación, Consejo Nacional de Política Económica y Social, Reforma del Sistema de Focalización Individual del Gasto Social, 62.

65 Departamento Nacional de Planeación, Consejo Nacional de Política Económica y Social, Reforma del Sistema de Focalización Individual del Gasto Social, 63. 
viviendas constituyen los factores de estratificación. Son estas las características de las viviendas (materiales de las fachadas, de las puertas o ventanas, antejardines, garajes, etc.), las características del entorno inmediato (vías de acceso, andén y focos de contaminación, entre otros) y el contexto urbanístico (zona y servicios públicos).

Los municipios y distritos pueden tener entre uno y seis estratos, dependiendo de la heterogeneidad social y económica de sus viviendas. Estos estratos son:

Estrato uno (1): bajo bajo.

Estrato dos (2): bajo.

Estrato tres (3): medio bajo.

Estrato cuatro (4): medio.

Estrato cinco (5): medio alto.

Estrato seis (6): alto.

Otros: uso diferente a vivienda (industria y comercio).

En la definición de los distintos estratos, la variable económica, sobre todo en lo relacionado con ingreso y patrimonio, es la de mayor peso. Los antecedentes familiares, el nivel de educación, de los usos y costumbres y la escala de valores de carácter regional y local tienden a relativizar tal variable, pero muchas veces no son tenidas en cuenta a la hora de formular soluciones a un problema. No es extraño que gente muy pobre, pero con niveles considerables de educación o procedentes de familias distinguidas arruinadas ocupen una posición social relativamente alta o que personas con bastante dinero, pero incultas, se ubiquen en un estamento menor.

Para el caso de este trabajo, denominaremos estratos socioeconómicos bajos a los ubicados entre el 1 y 2, de acuerdo con la anterior clasificación dada por el Departamento Nacional de Planeación. Se considera importante definir este parámetro, ya que es el utilizado por el Estado para fijar criterios de asignación de recursos a unos posibles beneficiarios o a unas poblaciones y se comparten los cuestionamientos que recibe de múltiples fuentes teóricas, sus muy fuertes implicaciones sociales y su "limitada" oportunidad de tener en cuenta otros factores de tipo estructural.

\subsection{La pobreza: del concepto al problema estructural}

El concepto de pobreza que se ha sustentado en la mayor parte de los trabajos sobre el tema es de "carencia" y se refiere a "un estado de deterioro, a una situación de deterioro que indica tanto una ausencia de elementos esenciales para la subsistencia 
y el desarrollo personal como una insuficiencia de las herramientas necesarias para abandonar aquella posición" ${ }^{66}$ Dichas carencias se refieren a dificultades más estructurales o más coyunturales, según sea la índole de los indicadores que se utilicen y, por ende, el método con el cual se mida y clasifique el fenómeno, como lo vimos en el ejemplo de la estratificación en nuestro país. En resumen, se es pobre cuando no se logra satisfacer algunos de los requerimientos definidos como "necesidades básicas", pero también se es pobre cuando, "aun cubriéndolas, los ingresos se ubican por debajo de una imaginaria línea de pobreza. Como resultante, se habla de pobreza estructural, de pobres por un escaso ingreso" ${ }^{67}$ Estas distinciones marcan algunas características de quienes se encuentran en esta condición $\mathrm{y}$, en todo caso, muestran que los primeros, independientemente del ingreso en el momento de la medición, han tenido dificultades para alcanzar índices mínimos de acumulación familiar.

En los diferentes conceptos de pobreza "aparece la idea de dificultad y de ausencia", ${ }^{68}$ pero los miembros que integran este universo de "pobrezas" reconocen diferentes orígenes: son el resultado de una variedad de situaciones previas y la imposibilidad de lograr condiciones de vida aptas para el ejercicio pleno de los derechos que le competen como ser humano. La situación de carencia y deterioro no solo compromete al presente, sino que involucran a las generaciones futuras, desde la perspectiva de la transferencia intergeneracional de la pobreza. Es casi un "círculo perverso", donde se reproducen las condiciones de marginalidad. Cuando se apela al concepto de carencia para describir una situación de pobreza, también se está haciendo referencia al "deterioro de los vínculos relacionales que se traduce en un alejamiento de la vida pública donde la presencia política o su influencia social se mantienen en el plano de lo formal antes que en el real". ${ }^{69}$

Esta línea que entiende pobreza como carencia es la que vincula las nociones de vulnerabilidad y de exclusión. Castel considera las situaciones de carencia en función de relacionar dos ejes: un eje de integración-no integración en relación con el trabajo, es decir, la vinculación con los medios por los cuales un individuo logra o no reproducir su existencia en el plano económico; otro, asociado a la inserción, o no, en una sociabilidad sociofamiliar, o sea, la inscripción o la ruptura

\footnotetext{
66 Nélida Perona, Carlos Crucella, Graciela Rocchi y Silva Robin, "Vulnerabilidad y exclusión social. Una propuesta metodológica para el estudio de las condiciones de vida de los hogares" http://www.ubiobio.cl/ cps/ponencia/doc/p15.4.htm 08/12/2013 (acceso diciembre 8, 2013).

67 Perona, Crucella, Rochhi, "Vulnerabilidad y exclusión social".

68 Perona, Crucella, Rochhi, "Vulnerabilidad y exclusión social".

69 Perona, Crucella, Rochhi, "Vulnerabilidad y exclusión social".
} 
con respecto al sistema relacional en el seno donde reproduce su existencia en el plano afectivo y social. ${ }^{70}$

La identificación de grupos sociales, hogares e individuos que se enfrentan a los riesgos mencionados no es necesariamente relacionado con su abordaje en pro de la resolución de sus problemas acumulados históricos por parte de políticas públicas; se consideraría, más bien, la reinterpretación de los contextos o de las diferentes fórmulas para su cualificación o estratificación como estrategias para redefinir su valor porcentual al final de unas cifras en gestión pública, que interpretan una buena gestión de los funcionarios del Gobierno de turno que son responsables del tema.

Frente a este tipo de problemáticas, los lineamientos de la política pública determinan acciones que se centran en los individuos y sus familias, más que enfrentar y abordar definitivamente el problema de pobreza de manera estructural y no continuar con propuestas individuales que no contemplan las realidades concretas y sí, por el contrario, los beneficiarios ingresan a las lógicas del capital financiero especulativo, como es el caso de las líneas de crédito educativo que veremos más adelante.

\section{Caracterización de la educación superior en Colombia y la política pública de inclusión de estratos socioeconómicos bajos}

\subsection{Antecedentes}

Al revisar los antecedentes históricos de la educación superior en Colombia, se encuentran aspectos que determinan la inequidad social que se ha venido instaurando en nuestra Nación y en América Latina. "Las propuestas dominantes formuladas hasta ahora no son satisfactorias, al menos en los países llamados subdesarrollados, la equidad social cuenta poco en esos ensayos de crecimiento económico", ${ }^{71}$ aspecto que no escapa al desarrollo presentado en el área educativa.

El sistema de educación superior en Colombia se ha caracterizado por ser fragmentado, tal como lo menciona Lucio "en la medida en que entre la década de

Robert Castel, "De la exclusión como estado a la vulnerabilidad como proceso", Archipiélago núm. 21 (1995): 28; Robert Castel, Les métamorphoses de la question sociale (París: Fayard, 1996), 18; Robert Castel, "Los desafiliados. Precariedad del trabajo y vulnerabilidad relacional", Topía I, núm. 3 (1991): 30.

71 Marta Lorena Salinas, Una política de inclusión en la universidad (Medellín: Universidad de Antioquia, 2008 ), 43. 
los años treinta y los setenta existió una ausencia de políticas estatales frente a la educación superior". ${ }^{72}$

El primer modelo de universidad ${ }^{73}$ en nuestro país fue uno de tipo confesional y otro de tipo laico; ejemplo de esto es la creación de la Universidad Javeriana en 1622 por parte de la comunidad de jesuitas y la reorganización de la Universidad Nacional, presentada por el liberal Uribe en 1909, que dio sus frutos hacia 1930, durante el período de Alfonso López Pumarejo y su Revolución en marcha.

Durante esta Revolución en marcha, en su reforma a la educación superior se habla de educación para todos, en el Decreto 1283 de 1935; allí se determina la "nivelación de los sistemas educativos para el campo y la ciudad y el inicio de la liberación de la tutela monopolizante de la Iglesia". ${ }^{74}$ Desafortunadamente, luego se evidencia que el planteamiento de la llamada "educación para todos" no queda más que en el papel y no se observan estrategias que permitan develar las formas mediante las cuales se implementaría tal reforma de la ley.

A partir de la década del cincuenta, a pesar de regresar el protagonismo de la Iglesia en la universidad, comienzan a crecer y a diversificarse las universidades públicas y las privadas. Surge la segunda industrialización del país, que busca la inmersión en un mercado dominado por Estados Unidos y es entonces que desde la educación se buscó la preparación de la clase dirigente y de los trabajadores, para acceder a esta propuesta de desarrollo con personal calificado en cada área.

Según Lucio, hacia la década del sesenta:

[...] continúa la ausencia del Estado con las formulaciones de una política universitaria, donde además, hasta este momento, aún no se tienen en cuenta las clases menos favorecidas y su inclusión en la educación superior muy a pesar de que la función del desarrollo educativo se refleja en el desarrollo socioeconómico de una comunidad. ${ }^{75}$

72 Ricardo Lucio y Mariana Serrano, La educación superior: tendencias y políticas estatales (Bogotá: Tercer Mundo Editores, 1988), 21

73 Lucio y Serrano, La educación superior, 67.

74 Lucio y Serrano, La educación superior, 71.

75 Lucio y Serrano, La educación superior, 48. 
La universidad termina ajustándose durante esta época a una universidad de élite, donde hay una sociedad monopolizada económica y políticamente; algo similar al ambiente actual.

Entre 1975 y 1990 se acentúa el fenómeno de la urbanización, sobre todo en las grandes urbes; con esto surge la expansión de instituciones de educación superior, tanto privadas como públicas y el incremento de estudiantes. Se produce como consecuencia un fenómeno llamado credencialismo:

[...] mediante el cual una porción de la población económicamente activa cuenta con títulos o credenciales educativas, con la correspondiente repercusión en los mercados del trabajo. En segundo lugar, la otra tendencia estructural tiene que ver con los costos crecientes, financieros y sociales que la expansión y diversificación llevó consigo. ${ }^{76}$

La expansión de la educación superior que se presenta a partir de la década del setenta responde a la gran cobertura que se ofreció en la educación secundaria para este momento y a la inserción de la mujer en la educación superior, lo que generó mayor demanda al sistema, en especial a partir de la década del ochenta, cuando empieza un incremento en los costos de la educación superior, que son asumidos en las instituciones públicas por el Estado mismo y en el ámbito de lo privado por el estudiante; en estas instituciones, el Estado solo aporta un 10\% de los ingresos.

De esta manera, se vislumbra cómo las posibilidades de inclusión de la población de estratos bajos a la educación superior, por lo menos desde el punto de vista económico, tiene desde ese momento serias dificultades, a causa de tal fenómeno. Hasta aquí mucho se habla de las estrategias de la educación superior para satisfacer la demanda de las clases medias emergentes de la educación secundaria, pero nada se menciona con respecto a la población de estratos bajos y sus posibilidades de acceso a la educación superior. "Para muchos el subsidio a la universidad pública es regresivo ya que no son propiamente los estratos sociales más desprotegidos quienes tienen acceso a ella actualmente" ${ }^{77}$

Con esa ampliación de la demanda de la educación superior, el Estado crea estrategias educativas dirigidas hacia la educación técnica y tecnológica, llamada en algunos sectores "educación para el trabajo" y que da cuenta de las expectativas de las clases

76 Lucio y Serrano, La educación superior, 70.

77 Lucio y Serrano, La educación superior, 70. 
medias y bajas en cuanto a educación se refiere. Esta tendencia se deja ver en el grupo poblacional que accede a la educación superior. Lucio (1988) plantea cómo "el sistema adjudica a cada grupo social un nivel específico de conocimiento". ${ }^{78}$ Según el origen social y la diversidad de calidad de la educación en el sistema, se tiene el acceso a la formación universitaria.

El ingreso a la educación superior en Colombia es inequitativo y esto se observa desde la educación primaria, donde se discuten las diferencias en los lineamientos de calidad de ambos sectores, el público y el privado; como lo menciona Lucio, "no son precisamente los más pobres quienes logran terminar el bachillerato en las mejores condiciones". ${ }^{79}$ Por eso se insiste en la necesidad del subsidio estatal de la universidad pública mediante el cual se brinde opción de acceso a la educación superior a quienes tienen condiciones para ingresar a ella, diferentes al costo económico.

Hacia la década del noventa, caracterizada por la apertura económica, nace la estrategia educativa de ciencia y tecnología, plasmada dentro del Plan de Desarrollo 1990-1994, que trae consigo las opciones de formación de personas en el exterior, el acercamiento de la universidad al sector productivo y la declaración en la Constitución del derecho a la educación, entre otras cosas.

Para los estudiantes de menores recursos económicos, el Estado diseña mecanismos financieros que permiten el ingreso y amplía los sistemas de subsidios por medio del Icetex, que parece, hasta este momento, ser la única estrategia de acceso de la población de estratos bajos a la educación superior.

Al observar el contexto en el que se desarrolla, el problema ha existido y sigue vigente, en el sentido de que aún hoy, quienes acceden a la educación superior siguen siendo parte de un fragmento de la sociedad privilegiada, en tanto poseen el recurso económico, lograron cumplir con el mérito o tuvieron las suficientes herramientas para continuar y culminar sus estudios.

La universidad de élite, donde accede quien mayor capacidad económica tiene, disuelve la opción de ingreso y acercamiento de estos grupos de población de estratos bajos a la educación superior; la ausencia del control del Estado, que se observa hasta la década del setenta, no promueve ningún tipo de política de inclusión; la

78 Lucio y Serrano, La educación superior, 46.

79 Lucio y Serrano, La educación superior, 47. 
universidad laica y la confesional no se cuestionan acerca de esta inclusión y las pocas opciones en cuanto a cobertura quizás influyeron en esta ausencia, así como lo hicieron la misma estratificación y discriminación social.

\subsection{Condiciones de ingreso a la educación superior}

Según la Ley 30 de 1992, se establecen los siguientes requisitos de ingreso a la educación superior: ${ }^{80}$

- $\quad$ Para todos los programas de pregrado, se debe poseer título de bachiller o su equivalente en el exterior y haber presentado el examen de Estado.

- Para los programas de especialización referidos a ocupaciones, se debe poseer el título en la ocupación afín.

- Para los programas de especialización, maestría y doctorado referidos al campo de la tecnología, la ciencia, las humanidades, las artes y la filosofía, se debe poseer título profesional o título en una disciplina académica.

El ingreso a los programas de formación técnica profesional en las instituciones de educación superior facultadas para adelantar programas de formación en ocupaciones de carácter operativo e instrumental requiere:

- Haber cursado y aprobado la educación básica secundaria en su totalidad.

- Haber obtenido el Certificado de Aptitud Profesional (CAP) expedido por el Servicio Nacional de Aprendizaje (SENA) o haber laborado en el campo específico de dicha capacitación por un período no inferior a dos años, con posterioridad a la capacitación del SENA.

\subsection{La política pública actual de acceso de estratos socioeconómicos bajos}

En el caso específico de esta política pública con las salvedades ya expuestas, encontramos una política pública con un enfoque de implementación tipo top down

80 Napoleón Murcia, "Imaginarios del joven colombiano ante la clase de educación física", Educación Física y Deporte núm. 26 (2008): 16. 
desde la clasificación de Yves Many ${ }^{81}$ y de governance. Top down, en la medida en que la formulación surge del centro hacia la periferia, sin una negociación previa con los agentes interesados en el tema. El proceso de su formulación e implementación obedece a lógicas jerárquicas, en las que el gobernante de turno tiene a dicha política dentro del discurso dominante para su período de mandato. De manera paralela, podemos pensar que esta política se ubica, según Alejo Vargas, en un contexto neorregulador en donde "la competencia fundamental de su formulación continúa a cargo del Estado institucional, pero la implementación de la misma tiende a privatizarse". ${ }^{82}$ Además el sistema de financiación se hace de forma tripartita (Estado, banca multilateral y usuarios).

El acceso a la educación superior en Colombia está enmarcado en los planteamientos del Plan Nacional de Desarrollo gubernamental (PND) actual, en el que se define un aumento en la cobertura de $19,7 \%$ en 1993 a 29\% en 2005 y se propone su incremento a $34,7 \%$. Según los datos encontrados para 2005, la tasa de cobertura va en $33,3 \% .^{83}$

Según el Departamento Nacional de Planeación, en el capítulo Subdirección de educación superior, la consecución de dicha tasa significa que "las posibilidades de desarrollo y bienestar del país dependen de que esta tendencia se mantenga dado el fuerte impacto de la educación en el bienestar de la población dada su alta rentabilidad individual y social". ${ }^{84}$ Las políticas planteadas por el DNP para dar cumplimiento a esta tasa de cobertura son: promoción y fortalecimiento de la educación técnica y tecnológica, desconcentración de la oferta de educación superior, financiamiento a la población pobre para el acceso a la educación superior, transformación del sistema para la financiación de la educación superior oficial y generación de alianzas entre las instituciones del sistema. ${ }^{85}$

Colombia aceptó los compromisos con las Metas del milenio. En desarrollo de este, se formuló el documento Conpes Social 91 de2005, Metas y estrategias de Colombia para el logro de los objetivos de desarrollo del milenio 2005-2015 y se organizó la Misión para el diseño de una estrategia para la reducción de la pobreza y la desigualdad, en el Departamento Nacional de Planeación, cuyo objetivo, además

\footnotetext{
Many y Thoening, "Marco conceptual", 62.

Vargas, Notas sobre el Estado y las políticas públicas, 54.

Ministerio de Educación Nacional, Lineamientos de politica para la atención, 12.

Departamento Nacional de Planeación, Hacia una Colombia equitativa e incluyente, 2005, 3.

Departamento Nacional de Planeación, Hacia una Colombia equitativa e incluyente, 2005, 3.
} 
de los estudios de base sobre pobreza en Colombia, es "proponer al Gobierno de Colombia una estrategia de largo plazo (15 años) para la reducción de la pobreza y la desigualdad". ${ }^{86}$

La Ley 1002 de 30 de diciembre de 2005 transformó el Instituto Colombiano de Crédito Educativo y Estudios Técnicos en el Exterior (Icetex), en una entidad financiera de naturaleza especial. En esta Ley se dice:

El Icetex tendrá por objeto el fomento social de la educación superior, priorizando la población de bajos recursos económicos y aquella con mérito académico en todos los estratos a través de mecanismos financieros que hagan posible el acceso y la permanencia de las personas a la educación superior, la canalización y administración de recursos, becas y otros apoyos de carácter nacional e internacional, con recursos propios o de terceros. El Icetex cumplirá con su objeto con criterios de cobertura, calidad y pertinencia educativa, en condiciones de equidad territorial. Igualmente otorgará subsidios para el acceso y permanencia en la educación superior de los estudiantes de estratos 1,2 y $3 .{ }^{87}$

En el Plan Decenal de Educación 2006-2016, "Pacto social por la educación", se contempla como macrometa "el acceso a la educación superior con equidad, pertinencia, permanencia y calidad para la población con SISBEN 1 y 2 que alcance niveles de excelencia y que decidan entrar al sistema". 88

El Plan Nacional de Desarrollo 2010-2014, "Prosperidad para todos", en el marco de la política de inserción de las familias en el sistema de protección social y de modo más directo dentro del componente del sistema de formación del capital humano, propone la ampliación de cobertura de la educación superior y plantea la necesidad de fortalecer la equidad, el acceso y el financiamiento de estudios superiores de la población más pobre del país, dado el impacto de la educación en el bienestar de la población, por su alta rentabilidad individual y social. Acorde con ello:

\footnotetext{
86 Francisco Javier Lasso, Incidencia del gasto público social sobre la distribución del ingreso y la reducción de la pobreza (Washington: Banco Mundial, 2004), 4.

87 Congreso de la República de Colombia, Ley 1002 de 2005, "Por la cual se transforma el Instituto Colombiano de Crédito Educativo y Estudios Técnicos en el Exterior, Mariano Ospina Pérez, Icetex, en una entidad financiera de naturaleza especial y se dictan otras disposiciones" (Bogotá: Diario Oficial No. 46.137, 30 de diciembre de 2005).

88 Ministerio de Educación Nacional, Lineamientos de politica para la atención, 4.
} 
[...] entre las estrategias y programas que se ejecutarán en el período 20062010 se contempla el financiamiento de la población pobre para el acceso a la educación superior, [...] ya que [...] del 20\% más pobre solo asiste el 3,8\% a la educación superior, mientras del 20\% más rico esta cifra es de 44,8\%. Para contrarrestar esta situación, la política propone otorgar: (1) subsidios o créditos educativos abiertos a todos los estudiantes pero con condiciones especiales a los estudiantes de bajos ingresos, a través del ICETEX para el pago de la matrícula, (2) subsidio de sostenimiento en el período de estudios, o (3) una combinación de las dos modalidades anteriores. ${ }^{89}$

\section{Conclusiones}

En Colombia es crítico el problema de una inclusión real y efectiva de los estratos socioeconómicos bajos, ya que los más pobres y sus voces están, de por sí, excluidos de la sociedad y con mayor vehemencia de las políticas públicas, cuya acción ha resultado ineficaz para contrarrestar el problema estructural. Se sabe que las políticas públicas no han cumplido con las funciones institucionales, sociales, políticas y administrativas que la sociedad espera de ellas y, por el contrario, se han convertido en un factor de desequilibrio; esto paradójicamente, las ha transformado en una fuente de permanentes tensiones entre el Estado central y las regiones; por ejemplo, se propone un lesivo retorno sin garantías laborales a los beneficiarios, con lo que se mantiene la segregación de los mismos y la distancia entre los grandes centros de discusión y toma de decisión y sus regiones de origen. La idea de conceder cupos a sectores de la sociedad que nunca hubieran ingresado en otras condiciones al sistema de educación superior es una forma positiva de brindar educación superior en este país; sin embargo, las políticas son como una fila de dominó, que provocan unas implicaciones tras otras.

El caso de la política de acceso tiene una historia de exclusiones sociales que solo se reivindican de modo parcial con la Constitución de 1991, el Estado colombiano, por ejemplo, no reconoce la diversidad étnica y cultural del país antes de esa fecha; este reconocimiento se traduce, a su vez, en la reivindicación de unos derechos más específicos como el derecho a la autodeterminación de los pueblos, a la educación, el respeto a la identidad, el acceso en igualdad de oportunidades a la investigación, la ciencia y la cultura. Luego, el siguiente paso fue la promulgación de la Ley 30 de 1992, que organiza el servicio público de la educación superior. No obstante,

89 Ministerio de Educación Nacional, Lineamientos de política para la atención, 4. 
esta no tipifica nuevas propuestas frente a grupos minoritarios o excluidos en el campo socioeconómico, entonces, carece de herramientas que expliciten nuevos servicios obligatorios frente a sus necesidades. El problema de una verdadera inclusión empieza a evidenciarse, cuando las sociedades reconocen estos derechos, lo que significa que estos habían sido negados.

Fuentes analizó el problema de la siguiente manera:

[...] el ascenso social se logra a través de los méritos de cada cual [...] pero finalmente no todos tienen el mismo capital cultural para acceder a él [...] pero el ascenso social de cada cual es acorde a sus derechos, por lo que existe una importante diferencia. El mérito puede ser recompensado sin justicia. Los derechos, por definición, no. ${ }^{90}$

¿La educación es un derecho o es un mérito? Desde aquí se ha replanteado el problema de las formas de selección, su legitimidad y su vigencia.

Sin embargo, aparece la dualidad de las normas y leyes colombianas, pues todos tenemos derecho a la educación, aunque solo algunos obtendrán un cupo por dos posibles vías. La primera, mediante la oferta de la universidad pública; la segunda, para quienes puedan costear la oferta privada mediante el cubrimiento de la matrícula o por medio de créditos con el Icetex que terminarán de pagar en los siguientes años a partir de su egreso.

Para retomar las teorías propuestas por Aguilar y Wildavsky, ${ }^{91}$ puede afirmarse que todos proponen modelos que lleven una:

[...] mejor acción del Estado frente a los problemas sociales, a una solución, a la creación de políticas y su implementación [y] tenga en cuenta que la política se hace por medio de procesos, a través de investigaciones con las comunidades, que conjugue todas las luchas de poderes en función siempre de resultados, que busque a la vez acciones de raíz, que utilice los recursos adecuadamente, pero que sobre todo analice el impacto en las sociedades. ${ }^{92}$

Fuentes, El sarko y sego, 72.

Antonio Aguilar, El desarrollo con enfoque de sustentabilidad (Guatemala: Tiempos modernos, 2002), 15.

Aguilar, El desarrollo con enfoque de sustentabilidad, 18. 
El problema que yace al interior es que el Estado no ha repensado una política que no solo incluya a los sectores menos favorecidos o representados étnicamente de la sociedad, sino también a todos aquellos que no tienen la posibilidad económica de realizarlo.

La universidad representa progreso en las sociedades, pero en Colombia no se han generado modelos horizontales en las políticas de acceso a la educación superior, "sino que a cada estrato le corresponde un tipo de institución". ${ }^{93}$ Entonces, ¿qué institución le corresponderá a las minorías étnicas, culturales y económicas en nuestro país? Esta estratificación educativa es una selección económica que realiza la sociedad de manera natural. Y agrega el autor:

[...] el acceso a la educación superior, entonces no es un problema técnico de mesura de habilidades intelectuales, sino que es un profundo e importante problema de orden social estructural que sigue vigente; sólo un margen estrecho de la población accede a la educación de alto prestigio y calidad en nuestro país. ${ }^{94}$

El primer obstáculo que enfrenta Colombia es la insuficiencia de la oferta de educación superior. Como lo afirman Gómez y Celis, "la demanda de educación superior ha venido aumentando en la medida en que la población y la economía van creciendo". ${ }^{95}$ El aumento en el número de graduados de la educación secundaria está creando un cuello de botella en el punto de entrada a la educación superior, dada la capacidad insuficiente del sistema público de educación superior y los altos costos para el estudiante de las instituciones privadas. Se requiere de una mayor oferta de educación superior pública, mas las limitaciones en el gasto público actual (déficit fiscal, presupuesto para la guerra, pago de la deuda externa y un alto costo en el funcionamiento del Estado $)^{96}$ impiden que el Gobierno incremente dicha oferta

93 Orlando Albornoz, "El acceso a la educación superior en América Latina y el Caribe" en La juventud universitaria en América Latina, ed. Juan Carlos Tedesco y Hans Blumenthal (Buenos Aires: Blumenthal, 1986), 45.

94 Albornoz, "El acceso a la educación superior en América Latina y el Caribe", 46.

95 Víctor Manuel Gómez y Jorge Enrique Celis, "Crédito educativo, acciones afirmativas y equidad social en la educación superior en Colombia", Revista de Estudios Sociales núm. 33 (2009): 32.

96 El gobierno nacional radicó el pasado 29 de julio el Proyecto de Presupuesto General de la Nación (PPGN) 2010 , que asciende a $\$ 148,3$ billones. Desde el punto de vista de las fuentes, este se financia con $\$ 136,5$ billones provenientes de recursos de la Nación y $\$ 11,8$ billones de los recursos propios de las entidades que hacen parte del PGN. Para la vigencia 2010 se proyectan recursos por $\$ 60,6$ billones con destino a las transferencias, que se dirigen principalmente al Sistema General de Participaciones (SGP) (39\%), pensiones (35\%) y en menor medida a las universidades, subsidios directos y contribuciones de nómina (Contraloría General de la Nación, 2010). 
por su cuenta y, por el contrario, aumenta la financiación de la política actual por medio de préstamos de la banca internacional.

Entre tanto, el Estado promulga la importancia de la educación, pues lo que resulta inexplicable o incoherente es que en todos los planes de desarrollo en Colombia desde la década del noventa, la cobertura ha sido un problema de primer orden, junto con el de la equidad. A pesar de la conciencia sobre el problema, las inversiones realizadas para el mejoramiento del sistema no son suficientes, como lo afirmaría Lucio y Serrano, "el porcentaje del PIB del país destinado a educación en las cifras de los planes de desarrollo resultan siempre insuficientes". ${ }^{97}$ Existen pocos cupos y muchos estudiantes que salen del bachillerato y que no están en condiciones de ingresar a la oferta privada y requieren competir con muchos estudiantes por un cupo. Como se enunció, el problema no solo radica en la cantidad de cupos o en la permanencia, sino en los factores sociales paralelos que no permiten la movilidad social en toda su magnitud; no es solo un asunto de la absorción de la demanda, sino de los factores alternos que no permiten que todos sean los elegidos.

Las políticas públicas de acceso a la educación parten del presupuesto de una educación desde y para individuos iguales, sin tener en cuenta la procedencia. Los estudiantes presentan los exámenes de ingreso con la creencia de que tienen el mismo capital cultural de sus "posibles" compañeros y piensan que la competencia es en iguales condiciones. Mas, en función de una sociedad más justa, ni las instituciones ni los estudiantes han pensado lo que tiene que hacer el Estado: realizar políticas que piensen en la otra Colombia, no la de las élites ni la de las masas, sino la de la educación de colombianos basada en los derechos, para los que tienen y no tienen las capacidades de acceder a ella por distintas razones.

En lugar de aumentar los cupos y las oportunidades en la educación superior pública, el costo de la educación ha sido transferido a estudiantes y familias de menores ingresos (privatización de la financiación de la educación superior). El crédito no puede sustituir ni reemplazar la necesaria inversión en mayores oportunidades públicas de educación. Lo que se requiere entonces son mayores inversiones en expansión de cupos y oportunidades en universidades públicas y más disponibilidad de crédito educativo para estratos socioeconómicos con mayor capacidad de endeudamiento y pago.

97 Lucio y Serrano, La educación superior, 62. 
El tema de privatización es un tema que está en constante discusión en la agenda pública universitaria y ha sido discutido en múltiples espacios de debate, ya que cada día son menos los recursos invertidos en educación superior y mayor la exigencia de autosostenimiento del Gobierno frente a las universidades públicas. Las partidas presupuestales para ciencia y tecnología al interior de las universidades públicas se han ido transformando en recursos para pagos de nómina y pasivo pensional. ${ }^{98}$ Esta situación exige alza en las matrículas, carencia de recursos para investigación y sobre todo una sociedad descontenta frente al apoyo del Gobierno al acceso a la educación superior en Colombia. Albornoz afirma que "para que existan cambios fundamentales en una educación se requieren de políticas de continuidad que oscilen entre cinco y veinte años" ${ }^{\prime \prime 9}$ para que se fortalezca el cambio, es decir, formular e implementar políticas de Estado.

Existen otros factores asociados con el problema del acceso a estudios universitarios. Por ejemplo, en Colombia carreras como Ingenierías, Arquitectura, Medicina y Derecho son las más escogidas por los estudiantes y existen otras que no tienen tanta demanda en el momento del ingreso. El problema no solo es el acceso en sí mismo, sino en la elección de carreras que han sido catalogadas como socialmente exitosas. Son los cupos para ciertas carreras los que se congestionan en las universidades y resultan muchos más excluidos en un número de programas determinados.

Se podría afirmar con Albornoz ${ }^{100}$ que "el gobierno, la maduración intelectual, la decisión a la hora de escoger carrera, las políticas de compensación, el problema económico, social, familiar, las pruebas de acceso, su intencionalidad", son factores de inclusión o exclusión al sistema de educación superior.

\section{Referencias}

Aguilar, Antonio. El desarrollo con enfoque de sustentabilidad. Ciudad de Guatemala: Tiempos modernos, 2002.

Aguilar Villanueva; Luis. La hechura de las políticas. México D. F: Porrúa, 1992.

Albornoz, Orlando. "El acceso a la educación superior en América Latina y el Caribe" en La juventud universitaria en América Latina, editado por Juan Carlos Tedesco y Hans Blumenthal, 31-67. Buenos Aires: Blumenthal, 1986.

\footnotetext{
Lucio y Serrano, La educación superior, 83.

99 Albornoz, "El acceso a la educación superior en América Latina y el Caribe", 33.

100 Albornoz, "El acceso a la educación superior en América Latina y el Caribe", 41.
} 
Brock, Karen, Andrea Corwall y John Gaventa. Power, Knowledge and Political Spaces in the Framing of Poverty Policy. Brighton: Institute Of Development Studies, 2001.

Canales, Andrea. "Expansión de la educación superior en Chile". http://www.revistahumanum.org/revista/expansion-de-la-educacion-superior-en-chile-hacia-un-nuevoenfoque-sobre-la-equidad-y-calidad-del-sistema/ (acceso junio 18, 2010).

Cantor, Viviana y Carolina Gómez. "Hacia una cultura inclusiva". Tesis de pregrado, Universidad Pedagógica Nacional, 2009.

Cárdenas, Catalina, Leonardo Gómez y Julio Solano. "Riesgos para la financiación de la educación superior". UN periódico, Sec. Educación, 8 agosto 2009.

Castel, Robert. "De la exclusión como estado a la vulnerabilidad como proceso". Archipiélago, núm. 21 (1995): 27-36.

Castel, Robert. Les métamorphoses de la question sociale. París: Fayard, 1996.

Castel, Robert. "Los desafiliados. Precariedad del trabajo y vulnerabilidad relacional". Topía I, núm. 3 (1991): 28-35.

Congreso de la República de Colombia. Ley 1002 de 2005, "Por la cual se transforma el Instituto Colombiano de Crédito Educativo y Estudios Técnicos en el Exterior, Mariano Ospina Pérez, Icetex, en una entidad financiera de naturaleza especial y se dictan otras disposiciones". Bogotá: Diario Oficial No. 46.137, 30 de diciembre de 2005.

Congreso de la República de Colombia. Ley 115 de 1994, "Por la cual se expide la Ley General de educación”. Bogotá: Diario Oficial No. 41.473, 5 de agosto de 1994.

Congreso de la República de Colombia. Ley 30 de 1992, "Por el cual se organiza el servicio público de la Educación Superior". Bogotá: Diario Oficial No.40.700, 29 de diciembre de 1992.

Congreso de la República de Colombia. Ley 48 de 1993, "Por medio de la cual el Estado fortalece la educación superior en las zonas apartadas y de difícil acceso". Bogotá: Diario Oficial No. 46350, 4 de agosto de 2006.

Contraloría General de la Nación. "Comentarios al proyecto de Presupuesto General de la Nación 2010”. http://www.contraloriagen.gov.co/c/document_library/get_file?folder Id=5709535\&name=DLFE-17016.pdf (acceso agosto 11, 2010).

Corte Constitucional. Sentencia T-689 de 30 de junio de 2005. M. P. Rodrigo Escobar Gil. Corte Constitucional. Sentencia T-780 de 12 de octubre de 1999. M. P. Álvaro Tafur Galvis. Dankhe, G. L. "Investigación y comunicación” en La comunicación humana: ciencia social, compilado por Carlos Fernández Collado y G. L. Dankhe, 34-35. México D. F: McGraw-Hill, 1989.

Departamento Nacional de Estadística. "Estadísticas vitales año 2002. Bogotá". http://www. dane.gov.co/files/investigaciones/discapacidad/marco_legal.pdf (acceso mayo 24, 2010). 
Departamento Nacional de Planeación, Consejo Nacional de Política Económica y Social.

Focalización del Gasto Social en las Entidades Territoriales, Conpes Social 022. Bogotá:

DNP, 1995.

Departamento Nacional de Planeación, Consejo Nacional de Política Económica y Social.

Focalización del Gasto Social, Conpes Social 040. Bogotá: DNP, 1997.

Departamento Nacional de Planeación, Consejo Nacional de Política Económica y Social,

Reforma del Sistema de Focalización Individual del Gasto Social, Conpes Social 055. Bogotá: DNP, 2001.

Departamento Nacional de Planeación. Hacia una Colombia equitativa e incluyente. Informe de Colombia objetivos de desarrollo del milenio. Bogotá: DNP, 2005.

Departamento Nacional de Planeación. Documento Conpes 102. Bogotá: DNP, 2006.

Duverguer, Maurice. Métodos de las Ciencias Sociales. Barcelona: Ariel, 1972.

Egler, María T. "El derecho a la diferencia en la igualdad de los derechos" en Manos y pensamiento: inclusión de estudiantes sordos a la vida universitaria, compilado por Claudia Rozo, 31-52. São Paulo: Kimpres Ltda., 2009.

Estrada, M. Políticas públicas de acceso de minorías a la educación superior en Colombia: Programa PAES. Bogotá: Unibiblos, 2008.

Ferreira, Francisco. La desigualdad en América Latina ¿Rompiendo con la historia? Serie Desarrollo para todos. Bogotá: Alfaomega colombiana, 2004.

Fuentes, Carlos. El sarko y sego: fundamentales y diferencias. Bogotá: Ariel, 2007.

Gómez, Víctor Manuel, Celis, Jorge Enrique. "Crédito educativo, acciones afirmativas y equidad social en la educación superior en Colombia". Revista de Estudios Sociales, núm. 33 (2009): 106-117.

Gómez, Víctor Manuel. "La política de equidad social y la transformación de la educación superior". Ponencia presentada al Coloquio Universidad, Estado, sociedad. Bogotá, 7-8 noviembre, 1996.

Guevara, René. "Minorías y universidad estatal en Colombia: aproximaciones a un estudio de políticas públicas universitarias". Ponencia presentada en Coloquio internacional Análisis y evaluación de políticas públicas en Colombia: experiencia, teorías y métodos en debate. Bogotá, 5 de noviembre, 2007.

Gutiérrez, Francisco Javier y Miguel Ruiz Rubiano. "El currículo flexible como respuesta a las necesidades educativas especiales en el aula regular". Tesis de pregrado, Universidad Pedagógica Nacional, 2008.

Instituto Colombiano de Crédito Educativo y Estudios Técnicos en el Exterior [Icetex]. "Medición de impacto del crédito educativo, acceso con calidad a la educación superior (Acces) Icetex". https://sinergia.dnp.gov.co/Sinergia/Archivos/027da492-9a34-45918856-6eb350f3910d/Ficha\%20_ACCESS.pdf (acceso 11 mayo, 2010). 
Instituto Colombiano de Crédito Educativo y Estudios Técnicos en el Exterior [Icetex].

Estadísticas actualizadas de beneficiarios con crédito educativo según indicadores-Línea ACCES-Icetex 2003-2007. Bogotá: Autor, 2008.

Lasso, Francisco. Incidencia del gasto público social sobre la distribución del ingreso y la reducción de la pobreza. Washington: Banco Mundial, 2004.

López, Mayra. Presentación realizada para los Rectores de ASCUN. Bogotá: Corcas editores Ltda., 2005.

Lucio, Ricardo y Mariana Serrano. La educación superior: tendencias y políticas estatales. Bogotá: Tercer Mundo Editores, 1988.

Many, Yves y Jean Claude Thoening. "Marco conceptual, aparición de los problemas públicos y la decisión pública" en Las políticas públicas, 89-108. Barcelona: Ariel, 1985. Mayorga, Martha Lilia. ¿Una inclusión excluyente? Una mirada a los requerimientos de un programa de inclusión en IES. Bogotá: Ministerio de Educación Nacional, 2008.

Ministerio de Educación Nacional. La revolución educativa. Bogotá: Autor, 2002.

Ministerio de Educación Nacional. Lineamientos de política para la atención educativa a poblaciones vulnerables. Bogotá: Autor, 2005.

Miñana, Carlos y José Gregorio Rodríguez. "La educación en el contexto neoliberal". http://funcomisionesmodep.org/index.php?option=com_joomdoc\&task=document. download\&path=ley-30\%2Fcarlos-minana-blasco-jose-gregorio-rodriguez-la-educacion-en-el-contexto-neoliberal (acceso junio 24, 2010).

Molina, Rocío. "Exploración y análisis de modelos de inclusión para las personas con discapacidad en educación superior". http://www.colombiaaprende.edu.co/html/ mediateca/1607/articles-132496_archivo.pdf (acceso abril 3, 2010).

Murcia, Napoleón. "Imaginarios del joven colombiano ante la clase de educación física". Educación Física y Deporte, núm. 26 (2008): 47-60.

Organización Mundial de Personas con Discapacidad. "Plan estratégico 2002 2006. Trabajando juntos para forjar nuestro futuro". http://latinamerica.dpi. org/3PLANESTRATEGICOOMPD_000.doc (acceso mayo 13, 2010).

Ortiz, Heidy Johanna y Bibiana Carolina Venegas. "Calidad y equidad para la población sorda en los exámenes de educación superior". Tesis de pregrado, Universidad Pedagógica Nacional, 2008.

Oszlak, Oscar. Estado y sociedad: las nuevas reglas de juego. Buenos Aires: Oficina de publicaciones del CBC, 1997.

Peláez, Diana, Johana Pinzón y Claudia Marcela Toscano. "Permanecer en el contexto universitario de la Universidad Pedagógica Nacional: Una propuesta para la permanencia de los estudiantes en situación de discapacidad". Tesis de pregrado, Universidad Pedagógica Nacional, 2009.

Pérez Morgan, Blanca. La inclusión de la niñez con discapacidad. Montevideo: Proder, 2002. 
Perona, Nélida, Carlos Crucella, Graciela Rocchi y Silva Robin. "Vulnerabilidad y exclusión social. Una propuesta metodológica para el estudio de las condiciones de vida de los hogares". http://www.ubiobio.cl/cps/ponencia/doc/p15.4.htm 08/12/2013 (acceso diciembre 8, 2013).

Real, Ingrid. "Adaptaciones curriculares en el grado transición". Tesis de pregrado, Universidad Pedagógica Nacional, 2004.

República de Colombia, Consejo Nacional de Política Económica y Social. Política nacional de competitividad y productividad. Bogotá: DNP, 2006.

República de Colombia. Constitución Política. Bogotá: Temis, 1993.

Rodríguez de Salazar, Nahir. "Proyecto Manos y pensamiento-Red de Instituciones Formadora de Formadores" en Manos y pensamiento: inclusión de estudiantes sordos a la vida universitaria, compilado por Claudia Rozo, 11- 34. Bogotá: Kimpres Ltda., 2009.

Román, Luis Ignacio. Pobreza, desigualdad de oportunidades y políticas públicas en México. México D. F: Fundación Konrad Adenauer, 2001.

Rosero, Lucía Mina. "Estratificación socioeconómica como instrumento de focalización". Economía y desarrollo, 3, núm. 1 (2004): 53-67.

Roth, Andre Nöel. "Conceptos, teorías y herramientas para el análisis de las políticas públicas" en Políticas públicas: formulación, implementación y evaluación, 17-107. Bogotá: Aurora, 2002.

Salinas, Marta. Una política de inclusión en la universidad. Medellín: Universidad de Antioquia, 2008.

Schiefelbein, Ernesto. Colombia: acceso y aprendizaje desde un ámbito internacional. Bogotá: Ministerio de Educación Nacional, 2003.

Subirats, Joan. Análisis de políticas públicas y eficiencia de la administración. Buenos Aires: Amorrortu, 1993.

Sverdlick, Ingrid, Paola Ferrari y Analía Jaimovich. Desigualdad e inclusión en la educación superior: Un estudio comparado en cinco países de América Latina. Buenos Aires: Ford Foundation, 2005.

Terricabras, Josep María. "Equidad” en Diccionario de Filosofía. Bogotá: Ariel, 2007.

Universidad Nacional de Colombia, Consejo Superior Universitario. Acuerdo 022, 2 de febrero de 1986.

Universidad Nacional de Colombia, Consejo Superior Universitario. Acuerdo 93, 23 de marzo de 1989.

Universidad Nacional de Colombia, Consejo Superior Universitario. Acuerdo 95, 11 de agosto de 1990.

Universidad Pedagógica Nacional. Acuerdo 027, Estatuto estudiantil, 23 de diciembre de 1993. Actualizado en noviembre de 2004. 
Valladares, María Angélica. Texto de apoyo para un proceso de integración educativa. Santiago: Fonadis, 2001.

Van de Walle, Dominique. "Incidence and Targeting: An Overview of Implications for Research and policy" en Public Spending and the poor. Theory and Evidence, 53-69. Baltimore: Banco Mundial, Johns Hopkins University Press, 1995.

Vargas, Alejo. Notas sobre el Estado y las políticas públicas. Bogotá: Almudena editores, 2001. Vega, Román. Evaluación de los efectos de la política de focalización de subsidios en salud y del SISBEN sobre la población vinculada, sin capacidad de pago, de las localidades de Bosa, Fontibón, Kennedy y Puente Aranda de Bogotá. Bogotá: Pontificia Universidad Javeriana, 2001.

Von Clausewitz, Karl. De la guerra. Barcelona: Idea Universitaria, 1999.

Von Wieser, Friedrich. Theorie der gesellschaftlichen Wirtschaft. Vienna: Social Economics, 1914. 